\title{
Over current and over voltage protection of permanent magnet brushless de motor using wavelet analysis
}

\author{
Valluru Hemanth Kumar ${ }^{1}$, M.V.Ramesh ${ }^{2}$ \\ ${ }^{I}$ (EEE Department, Prasad V. Potluri Siddhartha Institute of Technology, India) \\ ${ }^{2}$ (EEE Department, Prasad V. Potluri Siddhartha Institute of Technology, India)
}

\begin{abstract}
The objective of this paper is to develop Over Current and Over Voltage Protection of Permanent Magnet Brushless DC Motor (PMBLDCM) using Wavelet Analysis. The Motor's operating point is continuously changing with time and the motor is never operating at a constant speed throughout its operation. A Motor operating in a non-stationary environment has a non-stationary voltage and current signals. Fourier Transform (FT) cannot be used for analysis of non-stationary signals, because FT tells about which frequency components exist in the signal, but gives no time information about these frequency components. Short-Time Fourier Transform (STFT) was developed to solve this problem. STFT used a window function to view a part of non stationary signal as stationary and then perform analysis. However, STFT can have either good time resolution or good frequency resolution, but not both.

Wavelet Transform was developed to overcome this resolution problem. Wavelet Analysis uses contracted and expanded versions of a single prototype function called a wavelet. Fine time resolution can be achieved using contracted version of the wavelet and fine frequency resolution can be achieved using expanded version. Daubechies 4 wavelet is chosen for this application.
\end{abstract}

Keywords: PMBLDCM, Wavelet, Daubechies4, Over Current, Over Voltage.

\section{PMBLDCM}

\section{INTRODUCTION}

Brushless Direct Current (BLDC) Motors are one of the motor types rapidly gaining popularity in industries, traction, and electrical vehicles. BLDC Motor has a rotor with permanent magnet and stator with windings. As the name implies, BLDC Motors do not use brushes for commutation; instead, they are electronically commutated. With availability of efficient semiconductor switches, mechanical switching on commutator machines is eliminated. BLDC Motor control requires knowledge of the rotor position and mechanism to commutate the motor. To sense the rotor position BLDC Motors use Hall Effect sensors to provide absolute position sensing. BLDC Motors have many advantages over brushed DC Motors and induction motors. Some of them are better speed versus torque characteristics, high dynamic response, high efficiency, long operating life, noiseless operation, higher speed ranges. The ratio of torque delivered to the size of the motor is higher, making it useful in applications where space and weight are critical factors [1].

Electrical monitoring, which includes current based monitoring, is the most recent of all condition monitoring techniques and is inexpensive. The intention of this paper is development of a diagnostic scheme that uses readily available electrical signals in an electric motor, namely the motor stator current and supply voltage.

The condition monitoring, faults diagnostic, and protection become necessary in order to avoid extremely harmful failures of electric machines. The use of monitoring schemes for the continuous assessment of electrical machines is becoming increasingly important. The protection system for electric machines is basically designed to act only when a fault has occurred in order to initiate some remedial action. It is possible to provide acceptable warning of incipient failures using new condition monitoring techniques. It is also possible to schedule future preventive maintenance and repair work in addition to present maintenance needs. This can result in minimum downtime and optimum maintenance schedules. Faults diagnosis allows a machine operator to have the necessary spare parts before the machine is shut down, thereby reducing the costs of outage time and repairs [4].

\section{Construction}

BLDC Motors are a type of synchronous motor, the magnetic field generated by the stator and the magnetic field generated by the rotor rotates at the same frequency. BLDC Motors are available in single-phase, 2-phase and 3-phase configurations. Out of these, 3-phase motors are the most popular and widely used.

\subsection{Stator}


The Stator consists of stacked steel laminations with windings placed in the slots that are axially cut along the inner periphery. The windings are distributed in a different manner. There are two types of stator windings variants, trapezoidal and sinusoidal motors. The trapezoidal motor gives a back EMF in trapezoidal manner and the sinusoidal motor's back EMF is sinusoidal manner.

\subsection{Rotor}

The Rotor of BLDC motor is made of permanent magnet and can vary from two to eight pole pairs with alternate North $(\mathrm{N})$ and South (S) poles. Proper magnetic material is chosen for the required magnetic field density in the rotor.

\subsection{Hall Sensors}

To rotate the BLDC Motor, the stator windings should be energized in a sequence. It is important to know the rotor position in order to understand which winding will be energized in the energizing sequence. Hall Effect sensors are used to sense the rotor position. Most BLDC motors have three Hall Sensors embedded into the stator on the non-driving end of the motor. Whenever the rotor magnetic poles pass near the hall sensors, they give a high or low signal, indicating the North $(\mathrm{N})$ or South $(\mathrm{S})$ pole is passing near the sensors. Based on the position of the hall sensors, phase shift may be at $60^{\circ}$ or $120^{\circ}$ to each other. Based on this, the motor manufacturer gives the commutation sequence of the motor [2].

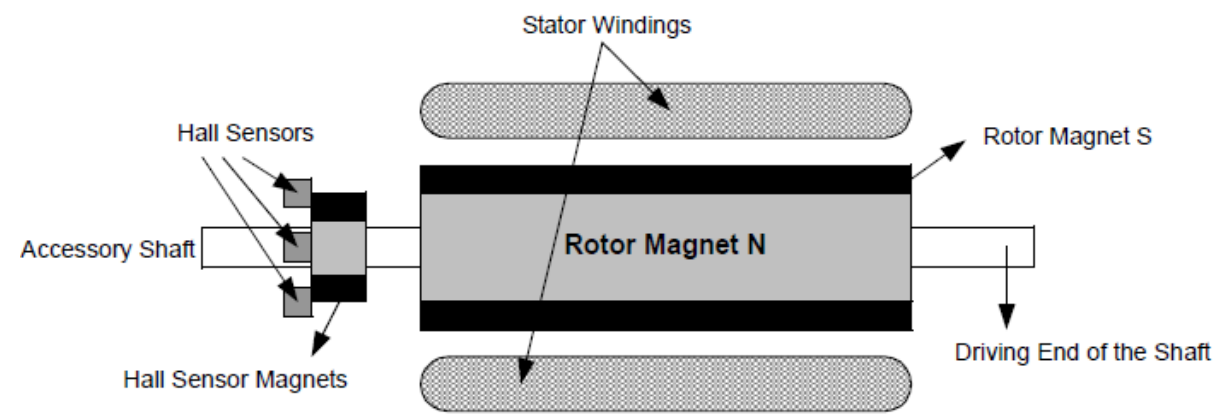

Fig. 1 Transverse section of a BLDC Motor

Figure 1 Shows Transverse Section of a BLDC motor with a rotor that has alternate N and S Permanent Magnets. Hall Sensors are embedded into the stationary part of the motor.

\section{Theory of operation}

Motor operation is based on the attraction or repulsion between magnetic poles. The process starts when current flows through one of the three stator windings and generates a magnetic pole that attracts the closest permanent magnet of the opposite pole. In order to keep the motor running, the magnetic field produced by the windings should shift position, and then the rotor moves to catch up with the stator field. In each commutation sequence, one of the windings energized to positive power (current enters into the winding), the second winding is energized to negative power (current exits the winding) and the third is in a non-energized condition. Interaction between the magnetic field generated by the stator coils and the permanent magnets produces torque. Ideally, the peak torque occurs when these two fields are at $90^{\circ}$ to each other and falls off as the fields move together [2].

\section{Fourier Analysis}

\section{Fourier Transforms}

Fourier analysis breaks down a signal into constituent sinusoids of different frequencies. Fourier analysis is as a mathematical technique for transforming our view of the signal from a time-based one to a frequency based one. In Fourier analysis signal is transforming to the frequency domain, time information is lost. When looking at a Fourier transform of a signal, it is impossible to tell when a particular event took place. This is the drawback in Fourier analysis.

If a signal doesn't change much over time called a stationary signal, this drawback isn't very important. However, most signals contain numerous non-stationary or transitory characteristics like drift, trends, and abrupt changes. These characteristics are often the most important part of the signal, and Fourier analysis is not suited to detecting those [3].

\section{Short-Time Fourier Analysis}


To correct the deficiency in Fourier analysis, Dennis Gabor (1946) adapted the Fourier Transform to analyze only a small section of the signal at a time, technique called windowing the signal. Short-Time Fourier Transform (STFT), maps a signal into a two-dimensional function of time and frequency.

STFT provides some information about both when and at what frequencies a signal event occurs. However, we can only obtain this information with limited precision, and that precision is determined by the size of the window. The drawback is that once you choose a particular size for the time window, that window is the same for all frequencies. Many signals require a more flexible approach one where we can vary the window size to determine more accurately either time or frequency [3].

\section{WAVELET TRANSFORMS}

Wavelet analysis represents the next logical step of a windowing technique with variable sized regions. Wavelet analysis uses long time intervals for more precise low frequency information, and shorter regions for high frequency information.

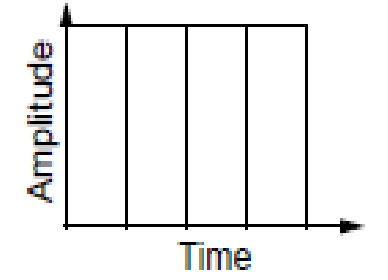

Time Domain (Shannon)

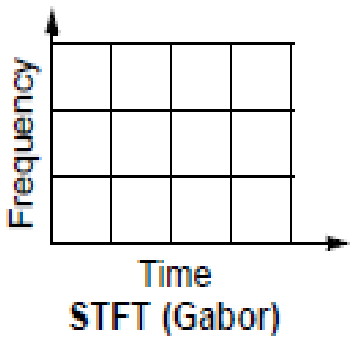

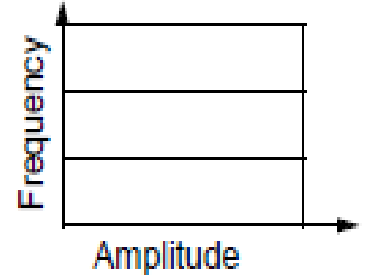

Frequency Domain (Fourier)

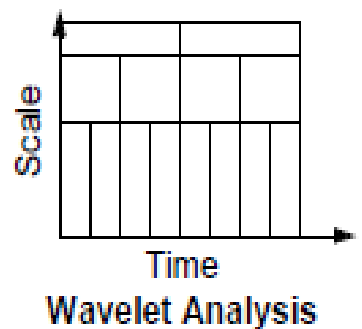

Fig. 2 Time, FT, STFT, WAVELET analysis general region representation

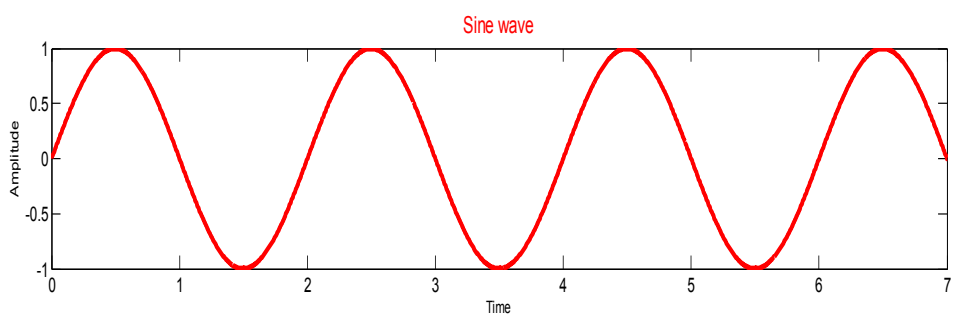

db4 Wavelet

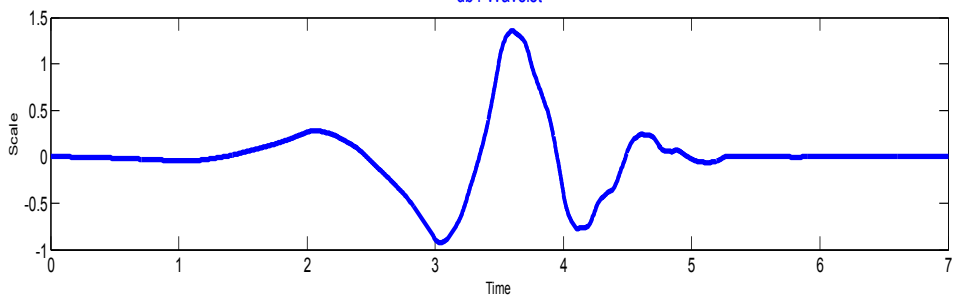

Fig. 3 General Sine wave and Wavelet signals

Wavelet analysis uses time-scale region. A wavelet is a waveform of effectively limited duration that has an average value of zero. Compare wavelets with sine waves, which are the basis of Fourier analysis. Sinusoids do not have limited duration they extend from minus to plus infinity. Sinusoids are smooth and predictable; wavelets are irregular and asymmetric.

In wavelet analysis signal is breaking into shifted and scaled versions of the original (or mother) wavelet. Signals with sharp changes might be better analyzed with an irregular wavelet than with a smooth sinusoid, just as some foods are better handled with a fork than a spoon. The wavelet multi resolution analysis is a new and powerful method of signal analysis well suited to fault generated signals. Wavelet analysis is based on the decomposition of a signal into scales using wavelet prototype function called mother wavelet. The 
temporal analysis is performed with a contracted, high frequency version of the mother wavelet, while the frequency analysis is performed with a dilated, low frequency version of the mother wavelet.

In this paper fault identification is based on wavelet multi resolution analysis (MRA) with Daubechies Four (Db4) wavelet by measuring sharp variations in the values of the voltages and currents for the three phases. The first stage MRA approximation signal extracted from the original signal is used to measure the variations in the voltage and current.
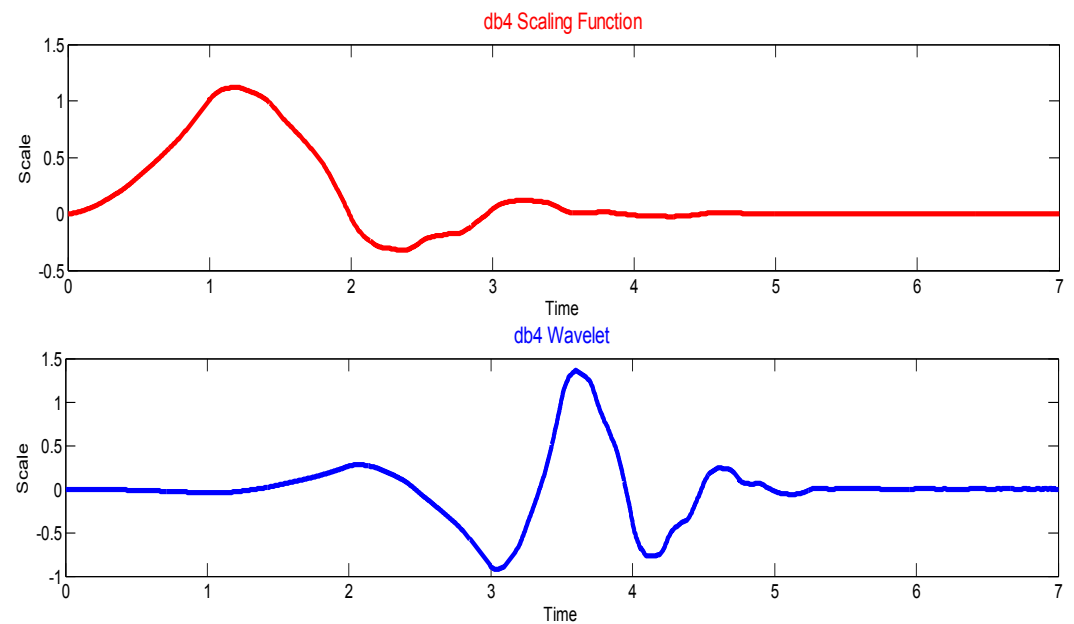

Fig. 4 Daubechies4 scaling function and wavelet function

\section{OVER CURRENTS AND OVER VOLTAGES}

Over current or excess current is a larger than intended electric current flows through a conductor, leading to excessive generation of heat, and the risk of fire or damage to equipment. Some of possible causes for over currents are short circuits, ground faults, failure of mechanical components, reduction in flux, failure of one of the phase of supply, failure of insulation excessive load, and incorrect design.

When the voltage in a circuit or part of it is raised above its upper design limit, this is known as overvoltage. Electronic and electrical devices are designed to operate at a certain maximum supply voltage, and considerable damage can be caused by over voltage. At the given rated voltage electric light bulb with a wire in it will carry a current just large enough for the wire to get very hot, but this hot not enough to melt it. The magnitude of current in a circuit depends on the voltage supplied. If the voltage is too high, then the wire may melt and the light bulb will be burned out. Similarly other electrical devices may stop working, or may even burst into flames if an overvoltage is supplied to the circuit.

A typical natural source of transient overvoltage events is lightning. When a fraction of a running load is suddenly switched off, the supply system voltage suddenly rises. When a big capacitor bank is switched on, the capacitive switching surge creates over voltages.

\section{BLOCK DIAGRAM AND DESCRIPTION}

The below block diagram shows the $1 \mathrm{Kw}, 500 \mathrm{~V}_{\mathrm{dc}}, 3000 \mathrm{rpm}$, 8-Pole PMBLDC Motor.

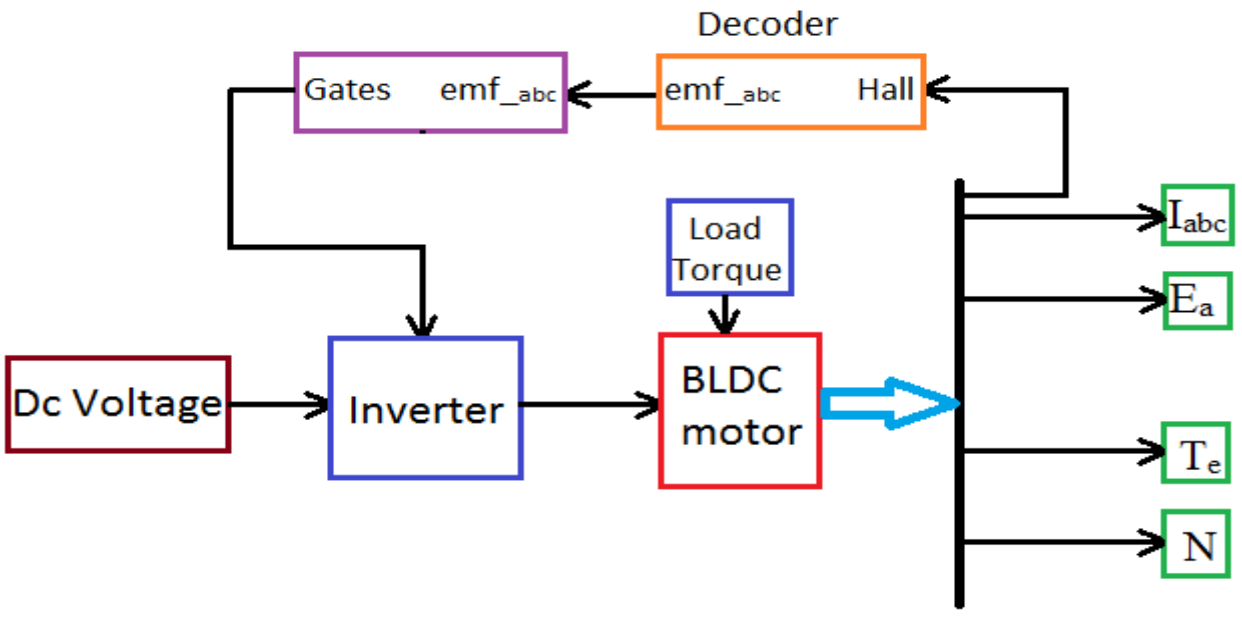




\section{Fig. 5 Block Diagram of PMBLDCM}

The 3-Ø Ac output voltage of the inverter is applied to stator windings of the PMSM. The inverter gates signals are created by decoding the Hall Effect signals of the motor. The Load Torque applied to the shaft of machine from 0 to its nominal value in steps.

The gate signals are developed according to the hall sensor signals, stator currents and inverter output voltages given to protection using wavelets block and this block produces the gate signals according to the logic written in that block.

This scheme is simulated in SIMULINK/MATLAB. When stator currents exceed the normal full load value, the wavelet decomposed approximation coefficient value of stator currents increases. The motor gets paused when this value greater than the value specified in the program.

The same logic is used to over voltage protection scheme. When inverter output voltage exceeds the rated voltage value, the wavelet decomposed approximation coefficient value of voltage increases. The motor gets paused when this value greater than the value specified in the program.

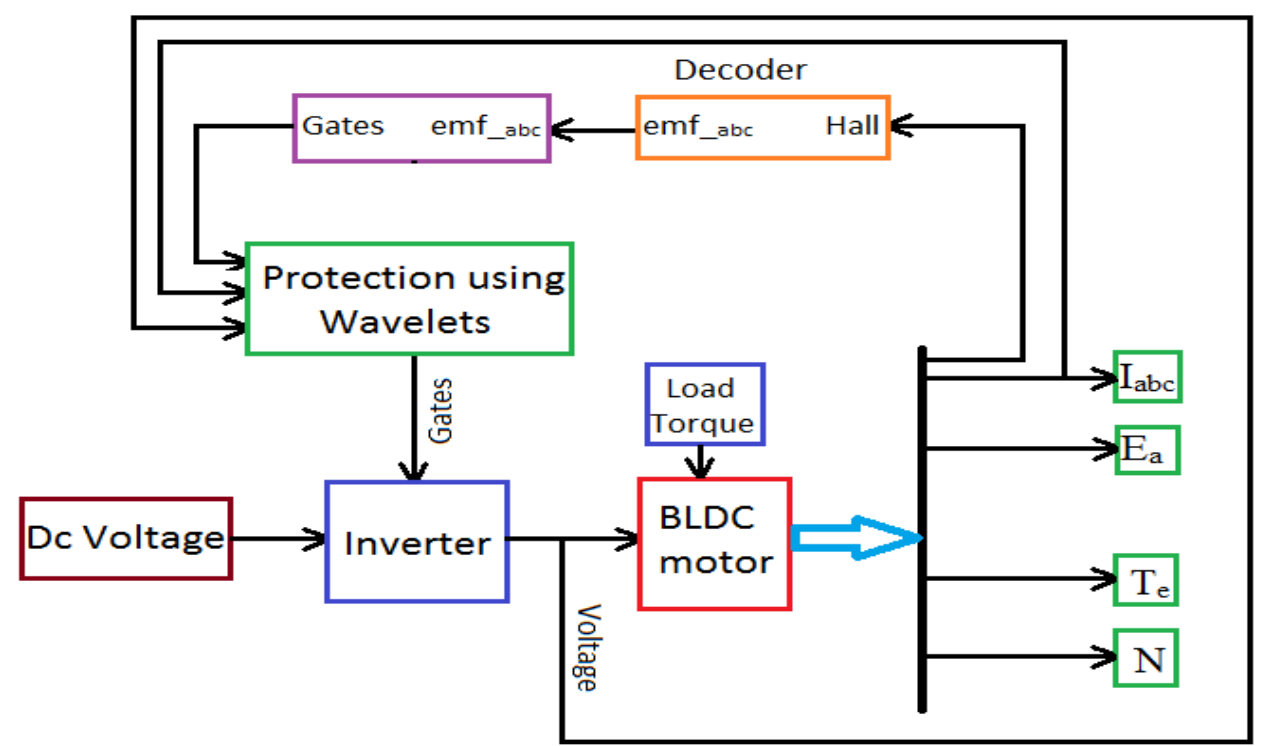

Fig. 6 Block Diagram of over current and over voltage protection scheme for PMBLDCM

\section{RESULTS}

Figure 7 and figure 10 shows the normal operating current and voltage waveforms of PMBLDC Motor respectively. Figure 8 shows the over current at $0.08 \mathrm{sec}$ without protection and Figure 9 shows the motor stopped at 0.08 to protect from over current with protection. Figure 11 shows the over voltage at 0.08 sec without protection and figure 12 shows the motor stopped at 0.08 to protect from over voltage with protection.

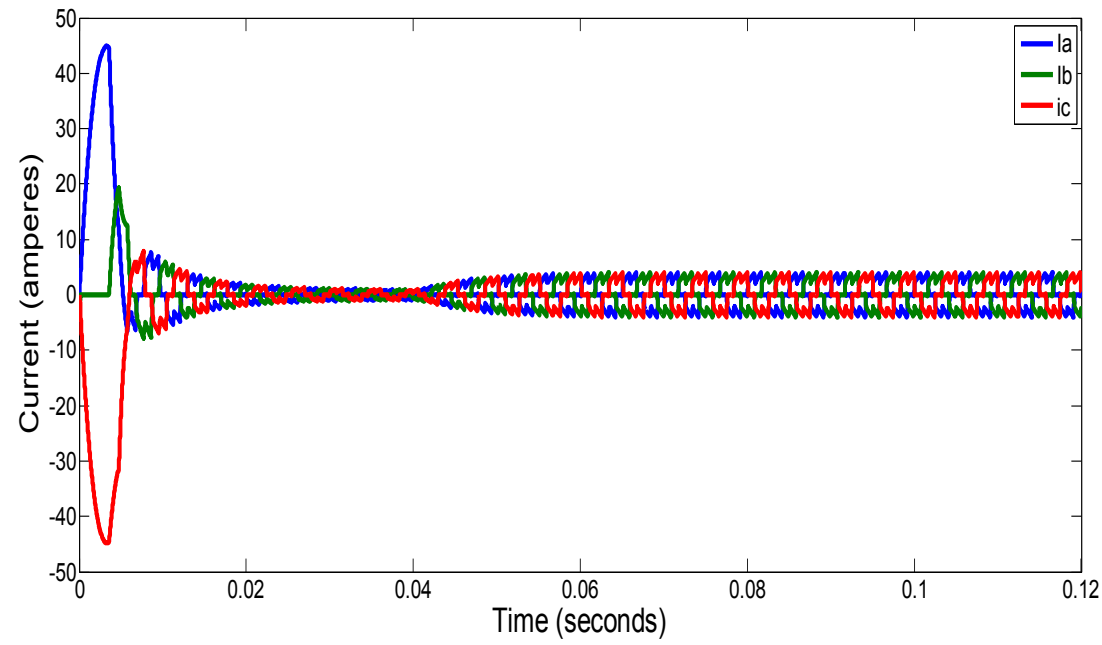

Fig. 7 3-Ø Current components of motor under normal operation 


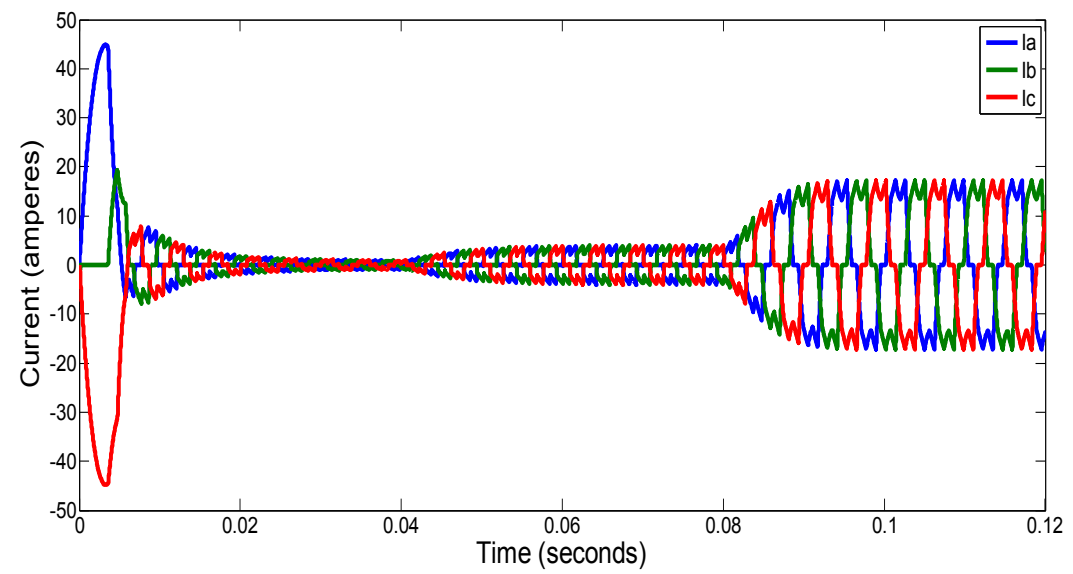

Fig. 8: 3-ø Stator currents of motor (over current at $0.08 \mathrm{sec}$ ) under abnormal operation without protection

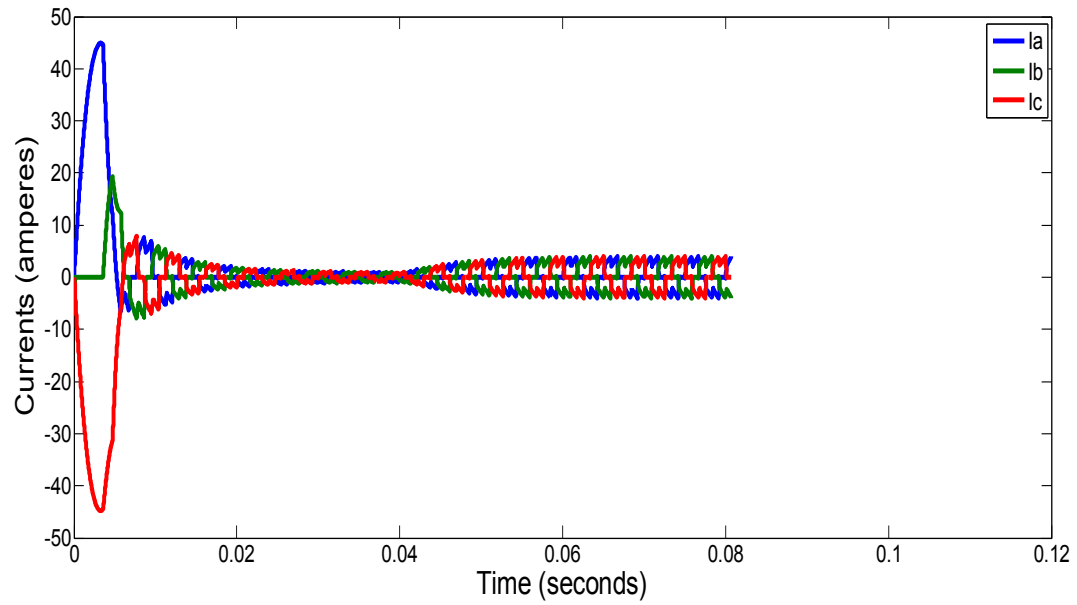

Fig. 9: 3-ø Stator currents of motor (motor stopped at $0.08 \mathrm{sec}$ ) under abnormal operation with protection.

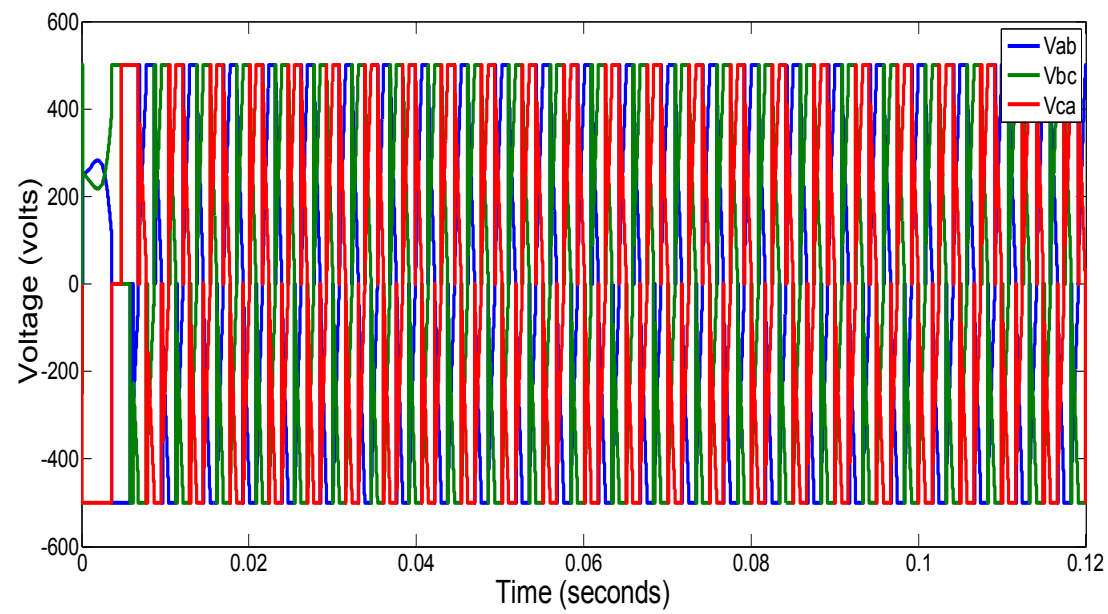

Fig. 10 3-ø Inverter output voltage of motor under normal operation 


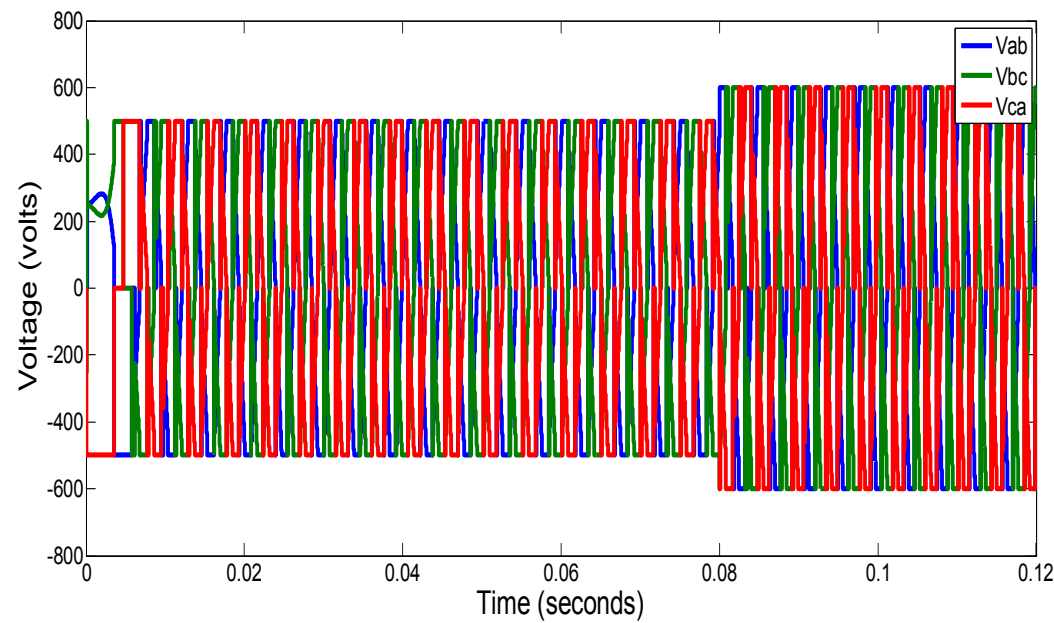

Fig. 11: 3-ø Inverter output voltage (over voltage at $0.0 .08 \mathrm{sec}$ ) under abnormal operation without protection.

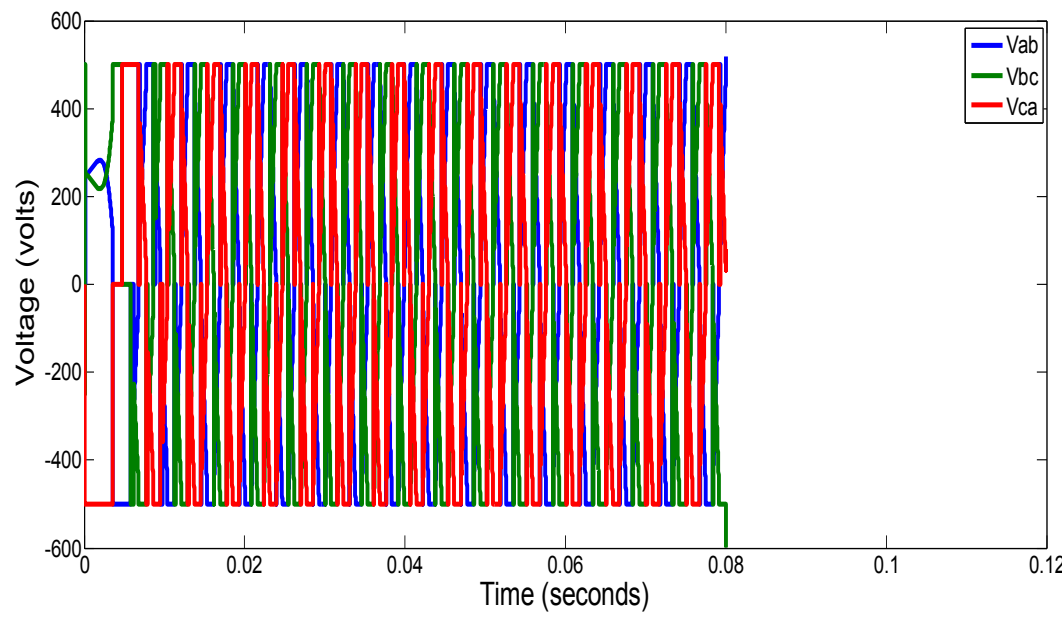

Fig. 12: 3-ø Inverter output voltage (motor stopped at 0.08 sec) under abnormal condition with protection

\section{CONCLUSION}

In this paper, over currents are experienced with the increase in load torque. Using two dc voltages with switch combination over voltage at specified time is obtained. Approximation and detail coefficients of obtained over currents and over voltages are calculated by using discrete wavelets. When the maximum of the approximation value exceeds the specified value than the PMDCM gets stopped. Simulation diagrams of figures 5 and 6 are simulated in SIMULINK/MATLAB and observed the waveforms shown in figures 7-12.

\section{REFERENCES}

[1]. Satish Rajagopalan, "Detection of rotor and load faults in brushless de motors operating under stationary and non-stationary conditions", Georgia Institute of Technology August 2006.

[2]. Microchip Technology, "Brushless Dc (Bldc) motor fundamentals, Application Note, An885, 2003.

[3]. Wavelet Toolbox Tm Version 4.13, User's Guide, By Michel, Misiti, Yves Misiti, Georges Oppenheim, Jean-Michel Poggi.

[4]. M. Abdesh Shafiel Kafiey Khan And M. Azizur Rahman, Wavelet based diagnosis and protection of electric motors (Memorial University of Newfoundland St. John's, N1, Canada,March 2010)

[5]. Awadallah, M.A; Morcos, M.M.; Gopalakrishnan, S.; Nehl, T.W., "Detection of stator short circuits in VSI-fed brushless Dc motors using wavelet transform," Energy Conversion, IEEE Transactions on , vol.21, no.1, pp.1,8, March 2006.

[6]. Daubechies, "Orthogonal bases of compactly supported wavelets," Communications on pure and Applied Mathematics, 1988

[7]. Awadallah, M.A; Morcos, M.M., "Diagnosis of stator short circuits in brushless de motors by monitoring phase voltages," Energy Conversion, IEEE Transactions on, vol.20, no.1, pp.246, 247, March 2005.

[8]. Kaplan, “The Daubechies D4 Wavelet Transform”, July 2001.

[9]. Douglas, H.; Pillay, P.; Ziarani, A.K., "A new algorithm for transient motor current signature analysis using wavelets", Industry Applications, IEEE Transactions on, vol.40, no.5, pp.1361, 1368, Sept-Oct 2004. 
Hemanth Kumar received the B. Tech degree in Electrical and Electronics Engineering from Gudlavalleru Engineering College in 2012 and pursuing M.Tech in Power System Control and Automation at Prasad V. Potluri Siddhartha Institute of Technology. His research includes Electrical Machines and Power System Operation and Control.

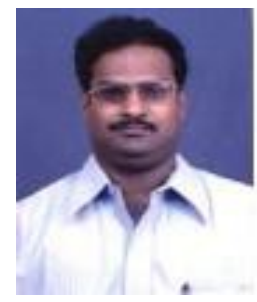

M.V.Ramesh received the B.Tech degree in Electrical and Electronics Engineering from Nagarjuna University in the year 1998 and M.S (Electrical Engineering) from German University in the year 2002. He is working as an Associate Professor at P.V.P.S.I.T, Vijayawada. His research interests include Power Electronics and Drives, Power System Automation, Hybrid Vehicle Design and Reactive Power Compensation. He published several papers at the national and international journals and conferences. 